\title{
Simultaneous Stabilization of Multimachine Power System Using Genetic Algorithm Based Power System Stabilizers
}

\author{
${ }^{(1)}$ Manisha Dubey, ${ }^{(2)}$ Aalok Dubey \\ Electrical Engineering Department ${ }^{(1)}$ \\ Maulana Azad National Institute of Technology, Bhopal \\ ${ }^{(2)}$ Dainik Bhaskar Group of Publications, Bhopal, \\ INDIA \\ http://www.manit.ac.in
}

\author{
NIKOS E. MASTORAKIS \\ WSEAS (Research and Development \\ Department), Agiou Ioannou Theologou \\ 17-23, 15773, Zografou, Athens, \\ GREECE,
}

Also: with the Hellenic Naval Academy, Hatzikyriakou 18539, Piraeus, GREECE

\begin{abstract}
This paper presents the simultaneous tuning of power system stabilizers in a multi-machine power system. The problem of selecting the parameters of power system stabilizers in converted into an optimization problem that is solved by genetic algorithm using eigen value based objective function. The dynamic performance of the system has been investigated under small perturbation and large disturbance. The performance of genetic algorithm based PSS has been compared with the conventional power system stabilizer. The non-linear simulation results on 4 machine, 11 bus system verifies the effectiveness of the proposed genetic algorithm based power system stabilizers.
\end{abstract}

Key-Words: - Dynamic stability, Genetic algorithms, Genetic algorithm based power system stabilizer, Power system stabilizer, Simultaneous stabilization

\section{Introduction}

Power systems are complex nonlinear systems and often exhibit low frequency electromechanical oscillations due to insufficient damping caused by adverse operating conditions [1]. Power system stabilizers (PSS) have been used widely for enhancing overall stability of the large power system [3]. The conventional fixed structure PSS comprising a cascade-connected lead-lag network with rotor speed deviation as input has made great contribution in enhancing system stability. However, the performance of the CPSS becomes sub-optimal following variations in system parameters and loading conditions [2]. In recent years, adaptive self tuning, variable structure, artificial neural network based PSS, fuzzy logic based PSS have been proposed to provide optimum damping to the system oscillations under wide variations in operating conditions and system parameters [4-6].

Recently, genetic algorithms (GAs) have received much attention for global optimization problems. GAs are heuristic population-based search methods that incorporate random variation and selection. GAs are iterative procedures that maintain population of candidate solutions to optimize a fitness function. The advantage of the GA technique is that it is independent of the complexity of the performance index considered. The application of GAs to tune the parameters of PSS have been reported [13]- [15]. In view of the above, the main thrust of the research work presented in this paper is to design power system stabilizers, which simultaneously stabilize the multimachine power system. The system dynamic performance has been studied with the GA based PSS and it is compared with the conventional PSS. The effectiveness of the GA based PSS (GPSS) has been investigated under small and large perturbations.

\section{System Model}

In this study a two area, eleven-bus-four-machine system is considered. Each synchronous machine is represented by non-linear sixth-order model as in the [3].The nominal system parameters and data are given in Appendix. All the four generators are provided with simple exciters and turbine governors

\section{Problem Formulation}

\subsection{Power System Model}

A power system can be modeled by a set of nonlinear differential equations expressed as

$$
\dot{X}=f(X, U)
$$

where $\mathrm{X}$ is the state vector and $\mathrm{U}$ is the input vector. The nonlinear model is described in Appendix. In

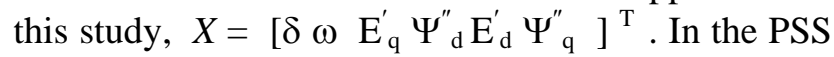
design, the linearized incremental models are employed .The state equation of the system can be described as

$$
\dot{X}=A X+\Gamma p
$$


where, $\mathbf{A}$ is a system matrix,$\Gamma$ is the perturbation matrix and $\mathrm{p}$ is the perturbation vector.

\subsection{Structure of PSS}

The power system stabilizer (PSS) considered, is the conventional lead-lag network with gain $\mathrm{K}_{\mathrm{c}}$ and leadlag time constants $T_{1}, T_{2}, T_{3}, T_{4}$ respectively and $T_{w}$ is the washout time constant, which is used to washout d.c. signals and without it, steady changes in speed would modify the terminal voltage. It can be described as

$$
U c=\frac{s T_{w} \cdot K_{c} \cdot\left(1+s T_{1}\right)\left(1+s T_{3}\right)}{\left(1+s T_{w}\right)\left(1+s T_{2}\right)\left(1+s T_{4}\right)} \Delta w
$$

where, $\Delta \omega$ is the rotor speed deviation in p.u. following a small perturbation in the system. The optimization problem namely the selection of PSS parameters are accurately determined using GA.

\subsection{Objective Function}

The GA employs an objective function based on eigenvalue. The performance index $\mathrm{J}$ is defined as $\mathrm{J}=\max \mathrm{R}(\lambda)$

where $\lambda$ is the closed-loop eigenvalue of the system.

Thus $\mathrm{J}$ is evaluated to maximize the damping of oscillatory modes for each individual .If damping ratio is less than 0.05 , then $\mathrm{J}$ is assigned infinity for that individual.

\subsection{Design Constraints}

The problem constraints are the parameter bounds. Thus the design problem can be formulated as the following optimization problem:

\section{Minimize J}

Subject to $\mathrm{K}_{\mathrm{C}}{ }^{\text {min }} \leq \mathrm{K}_{\mathrm{C}} \leq \mathrm{K}_{\mathrm{C}}{ }^{\text {max }}$
$\mathrm{T}_{1}{ }^{\text {min }} \leq \mathrm{T}_{1} \leq \mathrm{T}^{\text {max }}$
$\mathrm{T}_{2}{ }^{\text {min }} \leq \mathrm{T}_{2} \leq \mathrm{T}_{2}{ }^{\text {max }}$
$\mathrm{T}_{3}{ }^{\text {min }} \leq \mathrm{T}_{3} \leq \mathrm{T}_{3}{ }^{\text {max }}$
$\mathrm{T}_{4}{ }^{\text {min }} \leq \mathrm{T}_{4} \leq \mathrm{T}_{4}{ }^{\text {max }}$

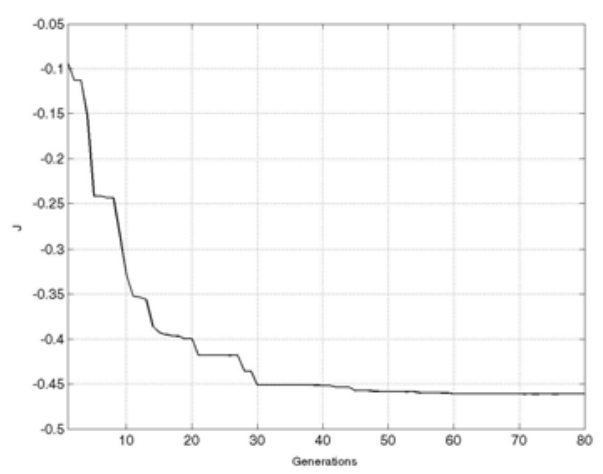

Fig. 1 Convergence rate during genetic search.
The proposed design algorithm employs genetic algorithm to optimize PSS parameters on all four machines simultaneously.

\section{Design of PSS}

\subsection{Proposed Genetic Algorithm}

The proposed genetic algorithms operate on a population of current approximations-the individuals- initially drawn at random. These individuals have the potential for the further improvement in the possible optimal solution. The convergence of the GA to a global optimal solution depends upon initial population span. Usually GAs operate on large size of initial population in order to avoid the local optimum solution at the cost of high computational time.

In the proposed algorithm a large size of initial population is generated. Each individual of current population is evaluated for $\mathrm{J}$ and a basis for the biased selection process is then established. The objective values obtained for each individual are mapped into fitness values through a ranking process. The higher the individual 's fitness, the higher is its chance to pass-on genetic information to successive generations. The fit individuals are selected for further genetic operations. The reduced size of the population results in low computational burden. The next generation will be populated with offspring, obtained from selected parents.

The entire population is replaced by offsprings using crossover and mutation in standard genetic algorithm [9], whereas in proposed Genetic Algorithm the parents are selected on the basis of fitness value and the b(Es)t parent chromosome is retained, Comparing the6fitness values of both the parents and the childrer(7) he best stings will go for the next generations. The GA stops when a predefined maximum number of generations is achieved or when the value returned by the objective function, being below a threshold, remains constant for a number of iterations.

The performance index of the best individuals in each generation is selected and plotted over the generations to show its convergence rate. Fig.1 represents the GA based optimization technique and depicts the convergence rate evolution of a population of 30 individuals, during a genetic process of 80 generations.

\section{Simulation Study}

To evaluate the effectiveness of the simultaneous tuned GA based PSS for improving stability of 
multi-machine power system, the dynamic performance of the proposed PSS was examined under small perturbation and large fault for the three loading conditions

- Nominal loading condition

- Heavy loading condition (the loads are increased from their nominal values)

- Light loading conditions (the loads are decreased from their nominal values)

\subsection{Small Perturbation Test}

A 5\% step decrease in $V_{\text {ref1 }}$ i.e. $\Delta V_{\text {ref1 }}=-0.05$ p.u. and $5 \%$ step increase in $\mathrm{V}_{\text {ref3 } 3}$ i.e. $\Delta \mathrm{V}_{\text {ref3 }}=0.05$ p.u. is given at $\mathrm{t}=0 \mathrm{sec}$., at nominal, heavy and light loading conditions.The dynamic responses for speed deviations are obtained with simultaneously tuned GA based PSS and compared with the conventional PSS optimized using phase compensation and no PSS in the system

The dynamic responses for speed deviations under small perturbation for nominal, light and heavy loading conditions are shown in Figures 2-7. The simulation results reveal that the genetic based PSS provide improved dynamic performance as compared to conventional optimum PSS (CPSS). It is clearly seen that the system oscillations are undamped without PSS and system responses are well damped with the genetic based PSS. The system returns to steady state much faster with the proposed GPSSs as compare to CPSSs.

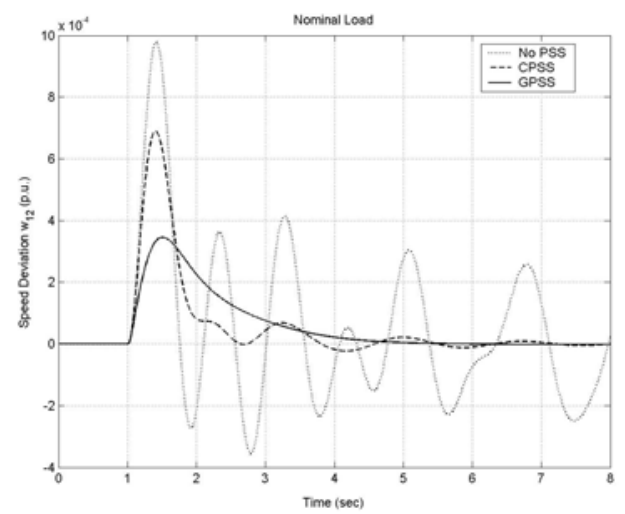

Fig. 2 Dynamic response for $\Delta \omega_{12}$ considering small perturbation for nominal loading conditions.

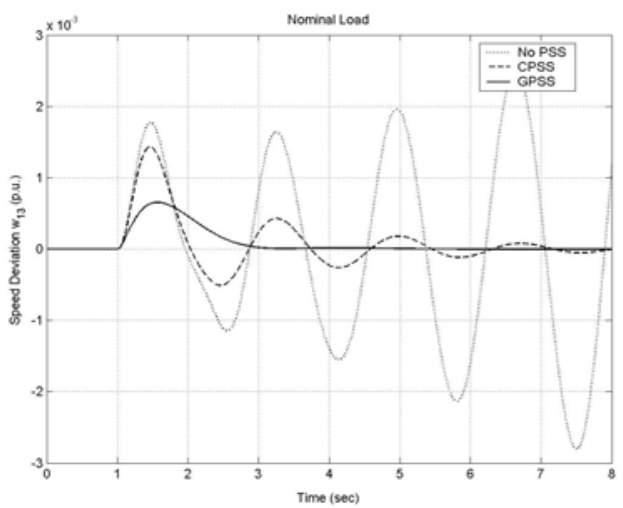

Fig. 3 Dynamic response for $\Delta \omega_{13}$ considering small perturbation for nominal loading conditions.

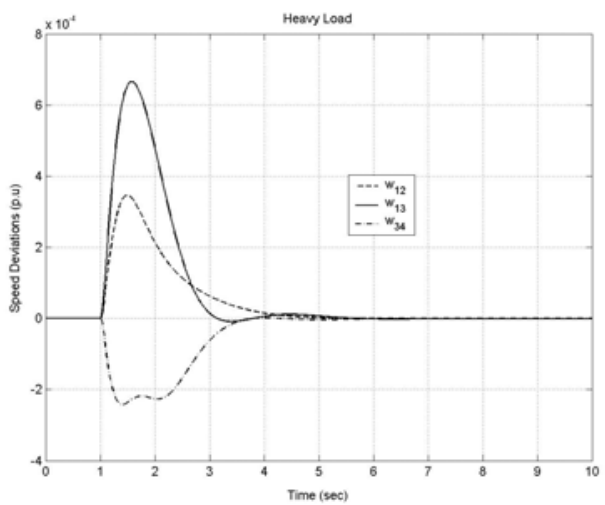

Fig. 4 Dynamic response for $\Delta \omega_{12}, \Delta \omega_{34}, \Delta \omega_{13}$ considering $\mathrm{V}_{\text {ref1 }}=-0.05$ p.u. and $\mathrm{V}_{\text {ref3 }}=$ 0.05 p.u. for heavy loading conditions with

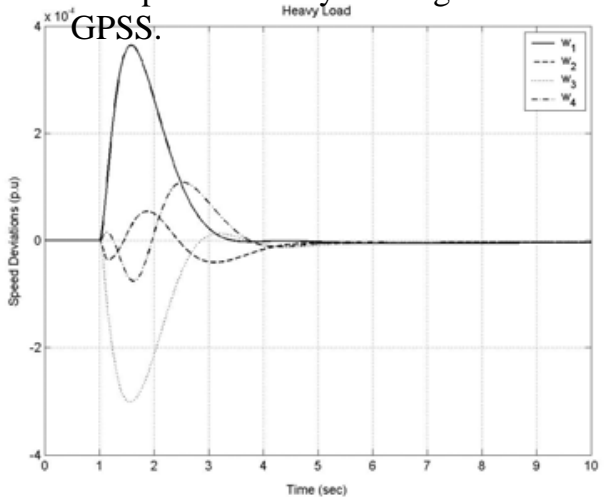

Fig. 5 Dynamic response for $\Delta \omega_{1}, \Delta \omega_{2}, \Delta \omega_{3}$ and $\Delta \omega_{4}$ under small perturbation for heavy loading conditions with GPSS. 


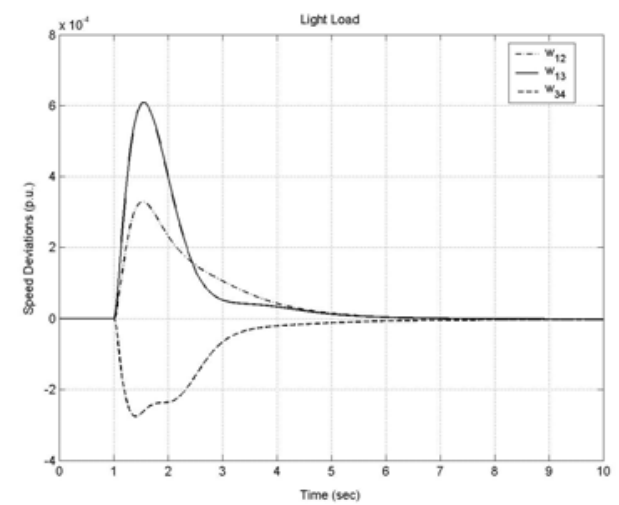

Fig. 6 Dynamic response for $\Delta \omega_{12}, \Delta \omega_{34}, \Delta$ $\omega_{13}$ considering $\mathrm{V}_{\text {ref } 1}=-0.05$ p.u. and $\mathrm{V}_{\text {ref3 }}$ $=0.05$ p.u. for light loading conditions with GPSS.

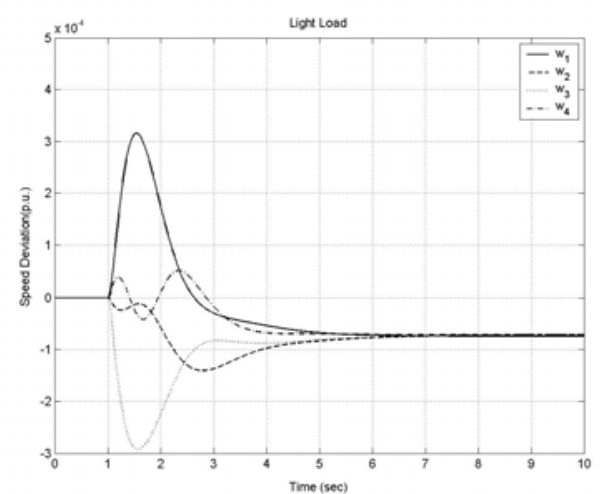

Fig. 7 Dynamic response for $\Delta \omega_{1}, \Delta \omega_{2}, \Delta \omega_{3}$ and $\Delta \omega_{4}$ considering $V_{\text {ref } 1}=-0.05$ p.u and $\mathrm{V}_{\text {ref3 }}=0.05$ p.u. for light loading conditions with GPSS.

\subsection{Large Disturbance Test}

To investigate the effectiveness of the GPSS under more severe conditions, a three-phase fault was applied at bus 7 for different loading conditions.

A three phase transitory fault of 3-cycle duration was applied at bus 7 at $\mathrm{t}=1.0 \mathrm{sec}$ for nominal, heavy and light loading conditions. The fault was cleared by tripping the faulty line. The dynamic responses for speed deviations are obtained with simultaneously tuned GA based PSS and compared with the conventional PSS and no PSS under the large disturbance.

It can be clearly seen from Figs.8-9 that the proposed GPSSs minimize the speed deviation and improve the settling time under the large disturbance also.

Figs. 10-11 shows that stabilizing signal of the CPSS and GPSS under large disturbance at nominal loading condition.

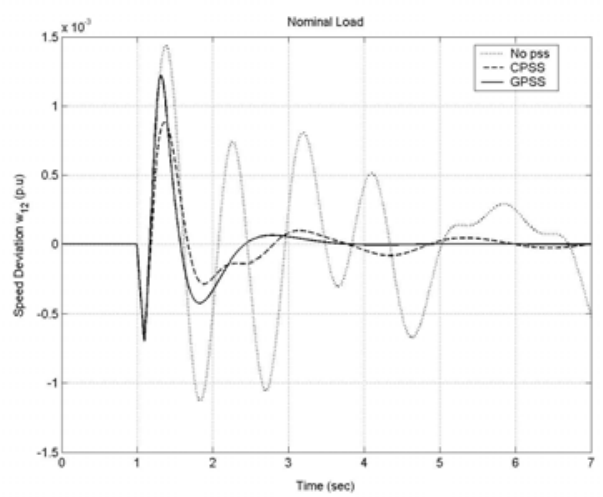

Fig. 8 Dynamic response for $\Delta \omega_{12}$ considering transitory 3-phase fault at bus-7 of three cycles duration for nominal loading conditions.

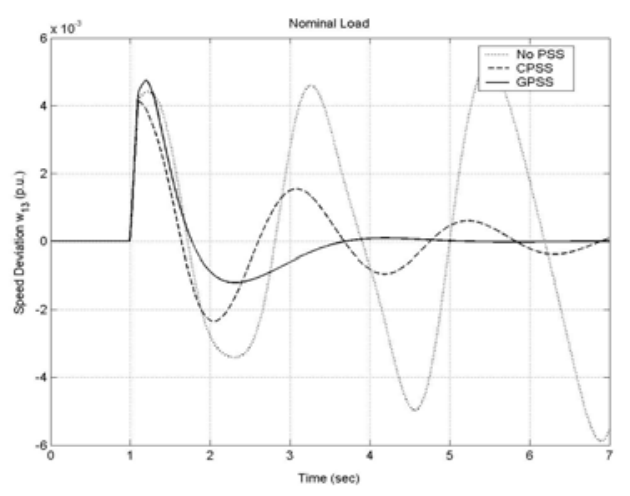

Fig. 9 Dynamic response for $\Delta \quad \omega_{13}$ considering transitory 3-phase fault at bus-7 of three cycles duration for nominal loading conditions.

The GPSSs provide much superior performance as compare to conventionally tuned power system stabilizer.

Figs. 10-11 shows that stabilizing signal of the CPSS and GPSS under large disturbance at nominal loading condition.

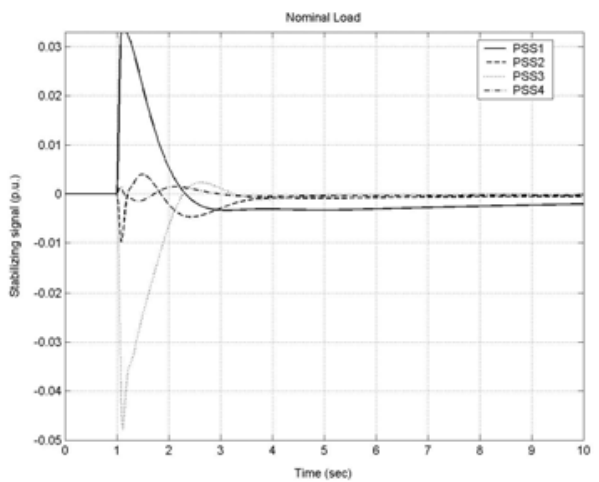

Fig. 10 Stabilizing signals of GPSS under small perturbation for nominal loading. 


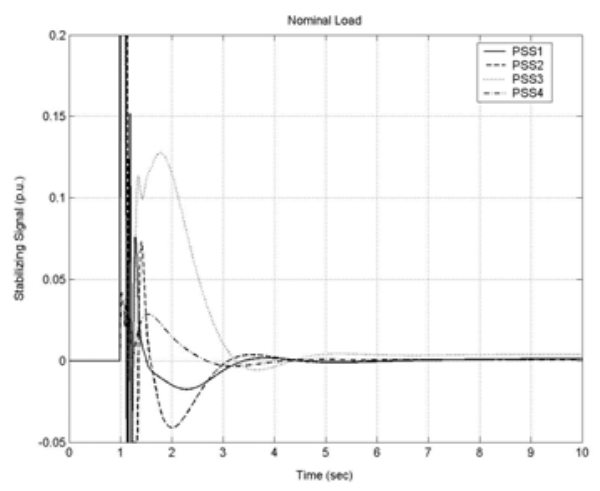

Fig.11 Stabilizing signals of GPSS under large disturbance at nominal loading.

The dynamic responses for $\Delta \omega_{12}, \Delta \omega_{34}, \Delta \omega_{13}$ considering a three phase transitory fault of 3-cycle duration at bus 7 at $t=1.0 \mathrm{sec}$ obtained for light loading conditions are shown in Fig12. The dynamic response for $\Delta \omega_{1}, \Delta \omega_{2}, \Delta \omega_{3}, \Delta \omega_{4}$ considering a three phase transitory fault of 3-cycle duration at bus 7 at $\mathrm{t}=1.0$ sec obtained for heavy loading conditions are shown in Figs13. The results shown in Figs 1213 clearly show that the system responses are well damped with GA based PSS as compare to conventionally tuned CPSS for light and heavy loading also.

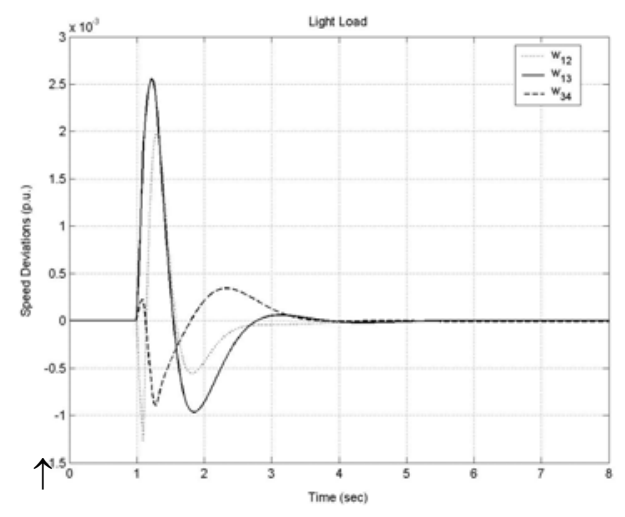

Fig. 12 Dynamic response for $\Delta \omega_{12}, \Delta \omega_{34}$, (p.u.) $\Delta \omega_{13}$ considering a transitory 3-phase fault at bus-7 of three cycles duration for light loading with GPSS.

\section{Conclusions}

This paper presents a systematic approach for the simultaneous tuning of power system stabilizers in a multimachine power system. The parameters of the stabilizers are simultaneously tuned using Genetic Algorithm. The dynamic performance of GA based

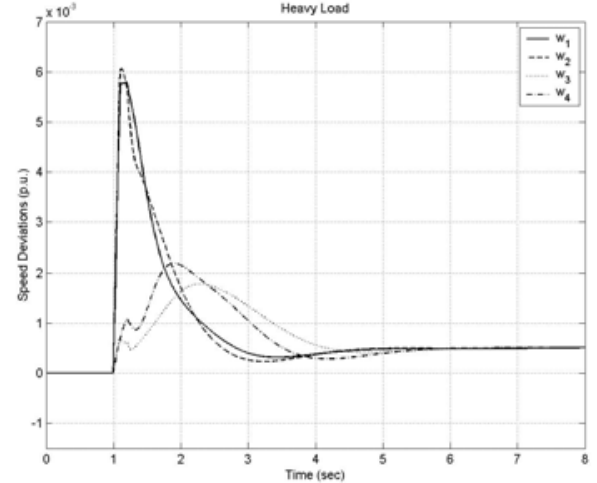

Fig. 13 Dynamic response for $\Delta \omega_{1}, \Delta \omega_{2}, \Delta$ $\omega_{3}$ and $\Delta \omega_{4}$ considering a transitory 3-phase fault at bus-7 of three cycles duration for heavy loading with GPSS.

PSS is superior to the conventionally tuned PSS. Simulation of the responses to small perturbation, large disturbance have demonstrated the effectiveness of the GPSS. The proposed GA employs reduction in population size therefore it reduces computational burden. Simulation studies also reveal that the proposed GPSS can damp both local and interarea modes of oscillations effectively.

\section{Appendix I}

Non-linear model of Multi-machine power system: $\mathrm{i}^{\text {th }}$ machine model :

$$
\begin{aligned}
& \rho \omega_{\mathrm{i}}=\left(\mathrm{T}_{\mathrm{mi}}-\mathrm{T}_{\mathrm{ei}}\right) / 2 \mathrm{H} \\
& \delta_{\mathrm{i}}=\omega_{\mathrm{o}}\left(\omega_{\mathrm{i}}-1\right) \\
& \rho \mathrm{E}_{\mathrm{qi}}^{\prime}=\left[\mathrm{E}_{\mathrm{fd}}-\left(\mathrm{E}_{\mathrm{qi}}^{\prime} .\left(\mathrm{X}_{\mathrm{di}}-\mathrm{X}_{\mathrm{di}}^{\prime}\right) \mathrm{I}_{\mathrm{di}}\right) / \mathrm{T}_{\mathrm{doi}}^{\prime}\right. \\
& \left.\rho \mathrm{E}_{\mathrm{fdi}}=\left[\mathrm{K}_{\mathrm{di}}\left(\mathrm{V}_{\mathrm{ref}}-\mathrm{V}_{\mathrm{ti}}\right)+\mathrm{V}_{\mathrm{si}}\right)-\mathrm{E}_{\mathrm{fd}}\right] / \mathrm{T}_{\mathrm{ai}} \\
& \mathrm{T}_{\mathrm{e}}=\mathrm{E}^{\prime} \mathrm{d}_{\mathrm{i}} \mathrm{I}_{\mathrm{di}}+\mathrm{E}^{\prime} \mathrm{q}_{\mathrm{i}} \mathrm{I}_{\mathrm{qi}}-\left(\mathrm{X}_{\mathrm{qi}}^{\prime}-\mathrm{X}_{\mathrm{di}}^{\prime}\right) \mathrm{I}_{\mathrm{di}} \mathrm{I}_{\mathrm{qi}} \\
& \mathrm{E}=\mathrm{E}_{\mathrm{qi}}^{\prime}-\left(\mathrm{X}_{\mathrm{d}}-\mathrm{X}_{\mathrm{d}}^{\prime}\right) \mathrm{I}_{\mathrm{di}} \\
& \delta_{\mathrm{ij}}=\delta_{\mathrm{i}}-\delta_{\mathrm{j}}
\end{aligned}
$$

\section{Appendix II}

The generation and terminal voltage of generator buses are as follows:
$\mathrm{G}_{1} \quad \mathrm{P}_{\mathrm{e}}=700 \mathrm{MW}$
$\mathrm{Q}_{\mathrm{e}}=185 \mathrm{VA}$
$\mathrm{V}_{\mathrm{t} .}=1.03 \angle 20.2^{\circ}$
$\mathrm{G}_{2} \quad \mathrm{P}_{\mathrm{e}}=700 \mathrm{MW}$
$\mathrm{Q}_{\mathrm{e}}=235 \mathrm{VA}$
$\mathrm{Vt}=1.01 \angle 10.5^{\circ}$
G3 $\mathrm{Pe}=719 \mathrm{MW}$
$\mathrm{Qe}=176 \mathrm{VA}$
$\mathrm{Vt}=1.03 \angle-6.8^{\circ}$
G4 $\mathrm{Pe}=700 \mathrm{MW}$
$\mathrm{Qe}=202 \mathrm{VA} \quad \mathrm{Vt}=1.03 \angle-17.0^{\circ}$ 
The generator parameters in per unit on the rated MVA and $\mathrm{kV}$ base are as follows:

$$
\begin{aligned}
& \mathrm{X}_{\mathrm{d}}=1.8 \quad \mathrm{X}_{\mathrm{q}}=1.7 \quad \mathrm{X}_{\mathrm{l}}=0.2 \quad \mathrm{X}_{\mathrm{d}}=0.3 \\
& \mathrm{X}_{\mathrm{d}}{ }^{\prime \prime}=0.3 \quad \mathrm{X}_{\mathrm{q}}{ }^{\prime \prime}=0.55 \quad \mathrm{R}_{\mathrm{a}}=0.0025 \quad \mathrm{~T}_{\mathrm{do}}{ }^{\prime}=8.0 \\
& \mathrm{~T}_{\mathrm{do}}{ }^{\prime \prime}=0.03 \quad \mathrm{~T}_{\mathrm{qo}} "=\quad \mathrm{A}_{\mathrm{sat}}=0.015 \quad \mathrm{~B}_{\mathrm{sat}}=9.6 \\
& \begin{array}{llll}
\text { sec. } & 0.05 \text { sec. } & \mathrm{A}_{\text {sat }}=0.015 & \mathrm{~B}_{\mathrm{sat}}=9.6 \\
\mathrm{X}_{\mathrm{q}}{ }^{\prime}=0.55 & \begin{array}{l}
\mathrm{T}_{\mathrm{qo}}{ }^{\prime}=8.0 \\
\text { sec. }
\end{array} & \Psi_{\mathrm{T} 1}=0.9 & \mathrm{~K}_{\mathrm{D}}=0
\end{array}
\end{aligned}
$$

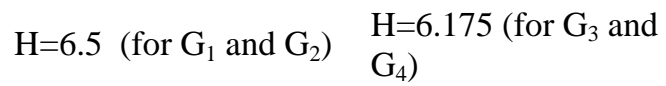

The loads and reactive power supplied $\left(\mathrm{Q}_{\mathrm{C}}\right)$ by the shunt capacitors at buses 7 and 9

$$
\begin{aligned}
& \text { Bus 7: } \mathrm{P}_{\mathrm{L}}=967 \mathrm{MW} \quad \mathrm{Q}_{\mathrm{L}}=100 \mathrm{MVAr} \text {, } \\
& \mathrm{Q}_{\mathrm{C}}=200 \mathrm{MVAr}
\end{aligned}
$$

Bus 9: $\mathrm{P}_{\mathrm{L}}=1767 \mathrm{MW} \quad \mathrm{Q}_{\mathrm{L}}=100 \mathrm{MVAr}$ $\mathrm{Q}_{\mathrm{C}}=350 \mathrm{MVAr}$

Excitation system $\quad \mathrm{K}_{\mathrm{A}}=50 \quad \mathrm{~T}_{\mathrm{R}}=0.01 \mathrm{sec}$.

Turbine-governor system $\quad \mathrm{Kg}=25 \quad \mathrm{Tg}=0.5$

\section{References}

[1]F.P. Demello and C. Concordia, "Concept of synchronous machine stability as affected by excitation control ", IEEE Transactions on PAS Vol. 88,1969, pp 316-329.

[2] E.V. Larsen and D.A. Swann, "Applying Power System Stabilizers”, Part I-III, IEEE Transactions on PAS Vol. 100, No. 6, 1981, pp. 3017-3046.

[3] P. Kundur, "Power System Stability and Control”, McGraw Hill Inc. 1993.

[4]Graham Rogers," Power System Oscillation”, Kluwer Academic Publishers, Boston, USA, 2000.

[5] P. Kundur, M. Klein, G.J Rogers and M.S Zywno, "Applications of Power System Stabilizers for Enhancement of overall system stability", IEEE Transactions on PAS, Vol .4, No-2, May 1989, pp. 614-626.

[6]Cheng S, Malik O.P., Hope G.S., "Design of selftuning PID stabilizer for a multimachine power system ”, IEE Proceedings, Part C, 1986; 133(4), pp. 176-185.

[7] Zhang, G.P. Chen, O.P. Malik and G.S. Hope, “ An artificial neural based adaptive power system stabilizer ", IEEE Transactions on Energy Conversion, Vol.8, No.1, March 1993, pp.71-77.

[8] D. E Goldberge, Genetic Algorithms in Search, Optimization, and Machine Learning, AddisonWesley publishing Company Inc., January 1989.

[9]Y.L.Abdel-Magid, M. Bettayeb, M.M. Dawoud, "Simultaneous stabilization of power systems using genetic algorithm", IEE Proceedings-
Generation, Transmission and Distribution, Vol.144, No.1, January 1997, pp. 39-44.

[10] K. Bhattacharya, J. Nanda, M. Aldeen and A. Kalam, "Tuning of power systemstabilizers in multi-machine systems using ise technique”, Electric Power System Research 46,1998,pp.119-131.

[11]M.A.Abido, Y.L.Abdel-Mazid, “A GeneticBased Power System Stabilizer ”, Electric Machines and Power Systems,, 26, 1998, pp. 559-571.

[12]M.A.Abido and Y.L.Abdel-Magid ,"Hybridizing rule-based power system stabilizers with genetic algorithms”, IEEE Transactions on Power Systems, Vol.14, May 1999,pp. 600-607.

[13] Y.L. Abdel-Magid, M.A. Abido, S. Al-Baiyat, and A.H. Mantawy, "Simultaneous stabilization of multimachine power systems via genetic algorithms," IEEE Transactions on Power Systems, Vol.14, Nov. 1999,pp.1428-1439.

[14] Manisha Dubey, P. Gupta, “ Design of Genetic Algorithm based Robust Power System Stabilizer”, International Journal of Computational Intelligence, Vol.2, No. 1, pp. 48$52,2005$.

[15] Manisha Dubey, Nikos E. Mastorakis, “ Design of Genetic Algorithm based Power System Damping Controller" WSEAS Transactions on Power Systems, Athens, Greece, Issue 5, Volume 1, May 2006, ISSN 1790-5060,pp.917923.

[16] Manisha Dubey, Nikos E. Mastorakis "Design of Genetic Algorithm based Damping Controller", IASME International Conference on energy \& Environmental Systems (EE06) Chalkida, Evia Island, Greece, May 8-13 2006, pp.132-138

[17] Nikos E. Mastorakis, "Solving Differential Equations via Genetic Algorithms", Proceedings of the Circuits, Systems and Computers '96 (CSC’96), Piraeus, Greece, July 15-17, 1996, 3rd Volume: Appendix, pp.733-737

[18] Gonos I.F., Mastorakis N.E., Swamy M.N.S.: “A Genetic Algorithm Approach to the Problem of Factorization of General Multidimensional Polynomials”, IEEE Transactions on Circuits and Systems I: Fundamental Theory and Applications, Part I, Vol. 50, No. 1, pp. 16-22, January 2003.

[19] Mastorakis N.E., Gonos I.F., Swamy M.N.S.: "Design of 2-Dimensional Recursive Filters using Genetic Algorithms", IEEE Transactions on Circuits and Systems I: Fundamental Theory and Applications, Part I, Vol. 50, No. 5, pp. 634639, May 2003. 